\title{
Gametocyte Carriages of Plasmodium falciparum (pfs25) and Plasmodium vivax (pvs25) during Mass Screening and Treatment in West Timor, Indonesia a Longitudinal Prospective Study
}

\section{Ayleen Alicia Kosasih}

University of Indonesia: Universitas Indonesia https://orcid.org/0000-0001-6470-1808

\section{Cristian Koepfli}

Notre Dame University

\section{Sopiyudin Dahlan}

PT Epidemiologi Indonesia

William A. Hawley

Centers for Disease Control

\section{J. Kevin Baird}

Oxford University: University of Oxford

Ivo Mueller

Walter and Eliza Hall Institute of Medical Research

Neil F. Lobo

Notre Dame University

Inge Sutanto ( $\nabla$ sutanto.inge@yahoo.com )

Universitas Indonesia https://orcid.org/0000-0003-2488-5133

\section{Research}

Keywords: gametocyte, pfs25, pvs25, Mass Screening and Treatment

Posted Date: December 1st, 2020

DOI: https://doi.org/10.21203/rs.3.rs-113860/v1

License: (c) (i) This work is licensed under a Creative Commons Attribution 4.0 International License.

Read Full License

Version of Record: A version of this preprint was published at Malaria Journal on April 9th, 2021. See the published version at https://doi.org/10.1186/s12936-021-03709-y. 


\section{Abstract}

\section{Background:}

Three rounds of mass screening and treatment (MST) demonstrated no effect on Plasmodium falciparum and $P$. vivax incidence in West Timor, Indonesia. This study nested within that trial evaluated the effect of MST on gametocyte carriage.

\section{Methods:}

Microscopy and PCR diagnostics were applied to study subjects through 3 months of MST involving dihydroartemisinin-piperaquine (DHP) and primaquine based on infecting Plasmodium species. RT-qPCR targeting the pfs 25 and $p v s 25$ sequences was conducted to detect and quantify gametocytes in blood samples of $P$. falciparum and $P$. vivax-infected subjects. Data from the baseline and endpoint were compared ( $p<=0.05$ as the significance threshold).

\section{Results:}

Between baseline and endpoint, prevalence remained unchanged for $P$. falciparum (6\% $=52 / 811$ versus $7 \%=50 / 740, p=0.838)$ and decreased slightly for $P$. vivax $(24 \%=192 / 811$ versus $19 \%=142 / 740, p=0.035)$. No significant difference was observed in gametocyte carriage rates for either $P$. falciparum $(43 \%=19 / 44$ versus $59 \%=23 / 39$, OR \& $95 \% \mathrm{Cl}=1.89,0.72-4.97)$ or $P$. vivax $(39 \%=49 / 125$ versus $37 \%=39 / 106$, OR \& $95 \% \mathrm{Cl}=0.90,0.51-1.59)$. Despite the insignificant differences between the two time points, the majority of positive subjects at the endpoint were newly parasitemic individuals (new infections) (Pf:92\%=46/50, Pv: $65 \%=93 / 142$ ). This result was similarly demonstrated for the transmissible stage - where new gametocyte carriers dominated endpoint positive subjects (Pf: 96\%=22/23, Pv: 95\%=37/39).

\section{Conclusion:}

Although three rounds of MST decreased individual parasitemia and gametocytemia based on diagnosis and treatment, this failed to impact malaria prevalence at a population level due to the development of new infected individuals that can sustain transmission. These observations in part explains why MST failed to impact transmission of malaria in this transmission context.

\section{Background}

Global malaria elimination by 2030 will require dramatic progress spurred by innovative approaches aimed at doing so [1]. One of the greatest obstacles may be the existence of large reservoirs of infection beyond the reach of conventional methods of malaria diagnosis.

Human-to-mosquito transmission requires the uptake of male and female gametocytes (sexual stages) by the mosquito [6]. A growing number of studies are being conducted towards the identification of super- 
spreader individuals that carry gametocytes and may contribute substantially to transmission in an area - pointing to the importance of treatment of the individual [7-10].

Gametocytes originate from the asexual cycle in humans. In an infected individual, a small proportion of the total parasites differentiate into gametocytes [6]. Plasmodium falciparum immature gametocytes sequester in the capillaries of inner organ until they mature, typically taking 10-14 days [6]. Since blood schizonticides do not kill mature gametocytes - they may be present 2-4 weeks post treatment [11-13]. Conversely, P. vivax development occurs concurrent to that of asexual parasites with treatment rapidly removing them from circulation $[6,14]$.

Asymptomatic infections of $P$. falciparum and $P$. vivax are common in varied transmission settings [1517]. These infections are often of low density and escape detection with microscopy or rapid diagnostic test (RDT) $[15,17]$. As gametocytes commonly constitute only $1-5 \%$ of all parasites in the blood [18], molecular methods, such as reverse-transcriptase qPCR (RT-qPCR) of gametocyte-specific transcripts, are increasingly used to detect and quantify this stage $[7-10,19]$.

Though frequently reported to be less infective compared to higher density symptomatic infections [2022], these asymptomatic infections may contribute substantially to transmission due to their high prevalence in communities [23]. It has been estimated that asymptomatic individuals are the source of up to $50 \%$ of transmission [15], thus, transmission stemming from asymptomatic infections may represent an important problem in control and elimination of malaria [24].

Mass drug administration (MDA) and mass screen and treat (MST) strategies have been developed and implemented as means of attacking that asymptomatic reservoir [2-5]. In MDA, treatment is given to all residents of a prescribed area without regard to infection status, whereas in MST treatment is only given to residents who test positive for infection.

We reported that three rounds of MST administered in cluster randomized fashion at sites in endemic West Timor in eastern Indonesia failed to diminish the incidence of malaria [5]. In order to better understand that finding, we specifically examined gametocyte carriage among residents living in those clusters.

\section{Methods}

\section{Study area}

This study was conducted in Wewiku subdistrict, Belu district, East Nusa Tenggara province, in eastern Indonesia (June-September 2013). The study area was reported to have the highest malaria endemicity in the province. The annual parasite index (API) per 1,000 population was 72 and 124 in 2011 and 2012 respectively (Belu district health office, personal communication), whereas in the entire East Nusa Tenggara province it was 25.8 and 21.1 during the same period [25]. Anopheles barbirostris was reported 
as the major malaria vector [5]. Other less dominant vectors included An. subpictus and An. vagus. A more detailed description on the study site has previously been reported [5].

\section{Sample Collection}

The original cluster-randomized trial evaluated the impact of MST conducted a) twice, and b) three times, both within 3 months [5]. Positivity for malaria parasites by microscopy was $8 \%$ in both MST at baseline, and $9 \%$ each at the last round of MST [5]. MST exerted no impact on measured incidence of diagnosed infections in both arms. In this analysis, round-1 of MST from both treatment groups were pooled and considered the 'baseline', while the last time-point from both groups was also pooled and considered the 'endpoint'.

Blood samples $(n=1551)$ were collected into EDTA tubes from 866 study subjects. All microscopypositive subjects were treated with dihydroartemisinin-piperaquine as a blood schizonticide, and primaquine ( $P$. falciparum: $0.75 \mathrm{mg} / \mathrm{kgBW}$ single dose, $P$. vivax. $0.25 \mathrm{mg} / \mathrm{kgBW} /$ day for 14 days). For RNA extractions, $50 \mu \mathrm{L}$ of blood was mixed with $250 \mu \mathrm{L}$ of RNAProtect (Qiagen) within 4 hours of collection, and stored at $-80^{\circ} \mathrm{C}$ until processing.

\section{Molecular Analysis}

Microscopic and PCR screening results have been reported in the parent study [5]. DNA quantification was performed by species-specific qPCR as described previously with some modification [26]. Details on the laboratory procedures are described in the Additional file 1. All $P$. falciparum and a set of randomly selected $P$. vivax positive samples underwent RNA extraction (Fig. 1) using the Quick RNA Mini-prep kit (Zymo Research, USA) according to manufacturer's instruction. $P$. falciparum and $P$. vivax gametocytes were quantified by two-step RT-qPCR of the gametocyte markers pfs 25 and pvs25 [27]. Transcriptor First Strand cDNA kit (Roche) was used to generate cDNAs for each sample in triplicates. During this first step, $4 \mu \mathrm{L}$ RNA was mixed with $2 \mu \mathrm{L}$ random hexamer, $1 \mu \mathrm{L}$ anchored oligo (dT) primers, $4 \mu \mathrm{L}$ RT buffer, $2 \mu \mathrm{L}$ dNTP, $0.5 \mu \mathrm{L}$ RNAse inhibitor, and $0.5 \mu \mathrm{L}$ Reverse Transcriptase enzyme for a final volume of $20 \mu \mathrm{L}$. The incubation temperature was $10 \mathrm{~min}$ at $25^{\circ} \mathrm{C}$, followed by $30 \mathrm{~min}$ at $55^{\circ} \mathrm{C}$, then $5 \mathrm{~min}$ at $85^{\circ} \mathrm{C}$. The tube was then immediately put on ice. The presence of mRNA transcript was verified using RT-qPCR targeting the $18 \mathrm{~S}$ rRNA [28]. Only samples positive for $18 \mathrm{~S}$ were analyzed for $p f s 25$ and $p v s 25$. The $p f s 25$ and pvs 25 qPCR was conducted in $12 \mu \mathrm{L}$ total volume containing $6 \mu \mathrm{L}$ FastStart Essential DNA SYBR Green master (Roche), $4 \mu \mathrm{L} \mathrm{cDNA}$, and $0.417 \mu \mathrm{M}$ each of previously published primers [29]. The cycle conditions were as follows: $10 \mathrm{~min}$ at $95^{\circ} \mathrm{C}$, followed by 45 cycles of $15 \mathrm{~min}$ at $95^{\circ} \mathrm{C}$ and $1 \mathrm{~min}$ at $58^{\circ} \mathrm{C}$. $\mathrm{T}$ for $P$. falciparum was $74-75^{\circ} \mathrm{C}$, and $79-80^{\circ} \mathrm{C}$ for $P$. vivax (Additional file 2). For quantification, series of plasmid harboring target sequence with concentration of $10^{5}, 10^{4}, 10^{3}, 10^{2}, 10,5$, and 1 copy per reaction were run in triplicate and a standard curve generated for each run. Negative (no template) controls were included in triplicates. The limit of detection (LOD) as assessed by running serial dilution of the plasmid in quintuples 
and determined as 10 copies $/ \mu \mathrm{L}$ for $p f s 25$ and $p v s 25$. Performance of the assay is described in Additional file 3. All triplicates of the cDNA were run and recorded as positive if a minimum of two of the three demonstrated a positive result. Quantities of the transcript were reported as the average transcript numbers of the replicates to the nearest CT values.

All laboratory analyses were performed blindly to subject identification (ID). Upon completion of all laboratory work, the results were linked to the subject ID, MST time point, and treatment status. All laboratory analyses were conducted at the Indonesian Medical Education and Research Institute (IMERI), Faculty of Medicine, University of Indonesia, Jakarta.

\section{Data analysis}

Categorical variables were analyzed using chi square test. Numerical variables were analyzed using Student's t-test when the distribution was normal or Mann-Whitney when it was not normal. 18S rRNA gene copies and pfs25/pvs 25 transcripts were log transformed for these statistical analyses. Linear regression was conducted to investigate the correlation between $18 \mathrm{~S}$ and $p f s 25 / p v s 25$ numbers. A pvalue $\leq 0.05$ was considered as statistically significant. All analyses were performed using SPSS version 23 (IBM, Armonk, New York).

\section{Results}

\section{Characteristic of the study subjects}

A total of 811 samples were collected at baseline and 740 at endpoint. These subjects represented $78 \%$ of the total parent study samples. Of the $102 P$. falciparum positive samples (baseline $=50$, endpoint $=$ 52), 83 were available for RNA extraction (Fig. 1). Of the 334 P. vivax positive samples (baseline $=192$, endpoint =142), 231 samples were available for RNA extraction (Fig. 1). Comparable demographic characteristics were observed among study subjects between baseline and endpoint (Table 1). Furthermore, 685 (84\%) subjects were sampled at both time points. 
Table 1

Characteristic of the study subjects

\begin{tabular}{|lll|}
\hline & Baseline & Endpoint \\
\hline Total subjects & 811 & 740 \\
\hline Age & & \\
\hline$<5$ y5-15 & $90(11.1 \%)$ & $88(11.9 \%)$ \\
$>15$ y & $177(21.8 \%)$ & $160(21.6 \%)$ \\
Unknown & $543(67.0 \%)$ & $490(66.2 \%)$ \\
& $1(0.1 \%)$ & $2(0.3 \%)$ \\
\hline Male (\%) & $387(47.7 \%)$ & $337(45.5 \%)$ \\
\hline
\end{tabular}

\section{pfs25 / pvs25 RT qPCR assay}

A single peak was demonstrated in the melting analyses of both pfs 25 and pvs 25 RT qPCR. PCR efficiency for $p f s 25$ and $p v s 25$ were $94.7 \%$ and $88.1 \%$, respectively. Both assays demonstrated $r^{2}$ of more than 0.98 (Pf: 0.986, Pv: 0.988) and LOD of 10 copies/ $\mu \mathrm{L}$ (Supplementary file S3 Assay performance).

For both species, gametocyte transcript numbers were positively correlated with $18 \mathrm{~S}$ gene copy numbers, with a stronger correlation observed for $P$. vivax than $P$. falciparum (Pf: $r=0.321, p<0.001 ; P v: r=0.778, p$ $<0.001$, Fig. 2A and B).

\section{Parasitemia (microscopy and/or PCR) and gametocyte carriage between baseline and endpoint}

Plasmodium falciparum: Between baseline and endpoint, no significant difference in prevalence was observed $(6 \%=52 / 811$ versus $7 \%=50 / 740, p=0.838)$ (Table 2, Fig. 1$)$. Furthermore, no significant difference was detected for the proportion of gametocyte positive infections $(43 \%=19 / 44$ versus $59 \%=23 / 39, p=0.189$ ) (Table 2, Fig. 1). The geometric mean pfs25 transcript numbers did not show any significant difference either (baseline: 132.5 transcripts/uL, Cl95 30.2-580.5, endpoint: 210.9 transcripts/uL, Cl95 56.8-782.7, t-test, $\mathrm{p}=0.625$ ) (Table 2).

A higher number of $p f s 25$ transcripts were observed among the subjects taking drug compared to those without drug (with drugs: 182.8, Cl95 29.1-1150.5, without drugs: 39.6, Cl95 3.3-472.1, t-test, $p=0.39$ ). Among gametocyte carriers, all children $<5$ year of age $(n=4), 80 \%(4 / 5)$ of school-aged children $(5-15$ $y)$, and $70 \%(7 / 10)$ adults ( $>15 \mathrm{y})$ were positive by microscopy and thus given drugs.

\section{Plasmodium vivax}

Although the proportion of parasitemic subjects was significantly lower at the endpoint compared to baseline $(23.7 \%=192 / 811$ versus $19.2 \%=142 / 740, p=0.035)$ (Table 2 , Fig. 1$)$, no significant difference was seen in the proportion of gametocyte positive infections $(39 \%=49 / 125$ versus $37 \%=39 / 106, p=$ 
0.786) (Table 2, Fig. 1) as well as the geometric mean of transcript numbers (56.4, Cl95 23.8-134.0 transcripts/uL and 65.6, Cl95 26.5-162.2 transcripts/uL, $p=0.810$ ) (Table 2).

Subjects identified for treatment harbored approximately 37-fold higher transcripts than the untreated carriers (geometric mean \& 95\%Cl: 356.6, 97.2-1309.8 versus 9.6, 5.1-18.2, t-test, $p<0.001$ ).

Table 2

Parasitemia and gametocyte carriages at baseline and endpoint by species

\begin{tabular}{|c|c|c|c|c|}
\hline & Baseline & Endpoint & $\begin{array}{l}\mathrm{p} \\
\text { value }\end{array}$ & OR $(95 \% \mathrm{Cl})$ \\
\hline Total subjects & 811 & 740 & & \\
\hline \multicolumn{5}{|l|}{ P. falciparum } \\
\hline $\begin{array}{l}\text { Positive by LM and/or } \\
\text { PCR }\end{array}$ & $52(6 \%)$ & $50(7 \%)$ & 0.838 & $1.06(0.69-1.61)$ \\
\hline No. screened for $p f s 25^{a}$ & 44 & 39 & & \\
\hline Gametocyte carriage (\%) & $19(43 \%)$ & $23(59 \%)$ & 0.189 & $1.89(0.72-4.97)$ \\
\hline Transcript numbers & $\begin{array}{l}132.5(30.2- \\
580.5)\end{array}$ & $\begin{array}{l}210.9(56.8- \\
782.7)\end{array}$ & 0.625 & $0.6(0.1-4.2)^{\mathrm{C}}$ \\
\hline \multicolumn{5}{|l|}{ P. vivax } \\
\hline $\begin{array}{l}\text { Positive by LM and/or } \\
\text { PCR }\end{array}$ & $192(24 \%)$ & $142(19 \%)$ & $0.035^{\star}$ & $0.77(0.59-0.98)^{\star}$ \\
\hline No. screened for $p v s 25^{b}$ & 125 & 106 & & \\
\hline Gametocyte carriage (\%) & $49(39 \%)$ & $39(37 \%)$ & 0.786 & $0.90(0.51-1.59)$ \\
\hline Transcript numbers & $56.4(23.8-134.0)$ & $65.6(26.5-162.2)$ & 0.810 & $0.9(0.2-3.0)^{c}$ \\
\hline \multicolumn{5}{|l|}{${ }^{a}$ Based on RNA availability } \\
\hline \multicolumn{5}{|c|}{${ }^{\mathrm{b}}$ Based on random selection and RNA availability } \\
\hline \multicolumn{5}{|l|}{ 'Mean ratio $(95 \% \mathrm{Cl})$} \\
\hline Abbreviation, LM: light mi & copy & & & \\
\hline
\end{tabular}

\section{Dynamic of parasitemic subjects and gametocyte carriers at baseline and final time point}

Every parasitemic subject and gametocyte carrier was justified individually at each timepoint, and their status was followed or traced backwards. Furthermore, parasitemic/gametocyte status was linked to whether or not they took antimalarial drugs. The drugs were given under direct observation of the field study team. 


\section{Plasmodium falciparum}

At baseline, 28 of 52 P. falciparum were microscopic positive and thus given drugs (Table 3 ). Of these subjects, 22 were followed at the endpoint and six subjects were lost to follow up. Of those 22, 20 were negative at endpoint while 2 remained positive (Fig. 3A). Among the 28 drug treated subjects, 15 were gametocyte carriers (Table 3 ). Ten of those 15 subjects were followed, and all were negative at the endpoint.

At the endpoint, on the other hand, there were 50 parasitemic subjects (Table 2). Of these subjects, 40 were negative at baseline, and 6 were not previously seen (Fig. 3A). The other four parasitemic consisted of two subjects with a previous drug treatment (originally from the 22 subjects taken drugs above), and two subjects without treatment (originally from 24 subjects without drugs above) (Fig. 3A, Table 3). Among the 50 parasitemic subjects, 23 were gametocyte carriers (Table 2). Of these carriers, 20 were negative at baseline, while the other 3 consisted of one carrier did not receive drugs and two subjects not seen at baseline (Fig. 3A).

\section{Plasmodium vivax}

At baseline, 54 of 192 parasitemic subjects were microscopic positive and thus given drugs (Table 3). Of these subjects, 50 were followed and included in the endpoint sample while four were lost to follow up. Of these 50, 44 were negative at endpoint while 6 were positive (Fig. 3B). Among the 54 subjects with drugs at baseline, 26 were gametocyte carriers (Table 3, Fig. 3B). Of these carriers, 23 were followed at endpoint and 22 were negative (Fig. 3B).

At endpoint, there were 142 parasitemic subjects (Table 2). Of these, 85 were negative at baseline, eight were newly diagnosed subjects, six were given drugs at baseline, and 43 were infected but not treated at baseline (diagnosed positive by PCR) (Fig. 3B). Among the 142 parasitemic subjects, 39 were gametocyte carriers (Table 2). Among these 39 carriers, 30 were negative at baseline, seven were newly diagnosed subjects, one was given drugs at baseline, one was without drug treatment (Fig. 3B). 
Table 3

Subjects with and without drug treatment at baseline

\begin{tabular}{|ll|}
\hline Description & \\
\hline Plasmodium falciparum & 52 \\
\hline Positive by LM (drug treated) & 28 \\
\hline Positive by PCR (not treated) & 24 \\
\hline Gametocyte carriage (pfs 25$)$ & 19 \\
\hline Drug treated & 15 \\
\hline Not treated & 4 \\
\hline Plasmodium vivax & 192 \\
\hline Positive by LM (drug treated) & 54 \\
\hline Positive by PCR (not treated) & 138 \\
\hline Gametocyte carriage (pvs25) & 49 \\
\hline Drug treated & 26 \\
\hline Not treated & 23 \\
\hline
\end{tabular}

\section{Discussion}

The current findings corroborate and help explain the observed failure of MST to impact malaria incidence. Despite delivery of effective therapy of patent malaria against all parasite stages, including gametocytes, insufficient asymptomatic reservoir clearance by this intervention resulted in new parasitemic and gametocyte carriers that appeared to sustain untrammeled transmission within MST clusters. [5].

Towards understanding the gaps in protection with the MST intervention, it is particularly important to understand the origin of new parasitemic subjects and gametocyte carriers. There are two possibilities for the source of these infections. First, since a high proportion of them were negative at baseline, these infections may stem from newly infected individuals (Fig. 3). Being negative at baseline, most of these subjects (parasitemic and gametocytemic) were thus not given drugs at baseline. In addition, many infections were at too low densities to be detected by light microscopy and thus were also not treated. Several studies have demonstrated that the numbers of parasites and gametocytes may fluctuate in the blood $[15,29]$ presenting the second possibility that a proportion of carriers, may have escaped a positive diagnosis with levels below the detection limit, and remained not given drugs at baseline. This was partly due to the sequestering parasites which resulted in a negative diagnosis - but were present and detectable at the endpoint [30]. In addition, it is possible that gametocytes in peripheral blood may constitute brief 
transience prior to more sustained sequestration in the shallow microvasclature of skin accessible to mosquitoes [31, 32]. We did not explore that possible anatomic compartment in the current study. Lastly, in $P$. vivax there may be a considerable proportion of the population that are bloodstage negative but may have dormant infections in their livers [33].

The actual impact MST has on transmission dynamics raises questions on its role in eliminating malaria. In this context, MDA complying with appropriate safety procedures may be considered over MST. The MDA approach would counter the gaps in protection seen with MST - here diagnostic limits of detection resulted in sustained transmission with a stable infectious reservoir of gametocytes. MDA studies have demonstrated that this approach may reduce incidence in low endemic malaria areas [2,34]. However, combining this approach with vector control was shown to have bigger impact to lower the incidence [2].

The limitation of this study is the design which is nested within a community trial. The lack of randomization in the design of this study may possess confounding factors - even though multiple criteria, such as age and gender, were comparable between groups (Table 1).

Nevertheless, this study demonstrated the presence of a substantial number of new parasitemic subjects and gametocyte carriers at the end of the MST trial - pointing to a limitation associated with the persistence of malaria transmission. Programs that consider MST as an intervention need to consider its mechanistic impact on malaria transmission, while also taking MDA into consideration in the drive towards malaria elimination.

\section{Declarations}

\section{Acknowledgement}

We would like to thank the field team (Dedi R. Simanjuntak, Tri A. Larasati, Cathy Wabang and Emerensiana Meno) for their dedication and hard work. We also thank the IMERI head of infectious diseases and immunology research cluster Dr. Erni J. Nelwan, and members (Suwarti, Yunita Windi Anggraini and Mila Amalia) for their support and assistance. We also appreciate the outstanding work from laboratory staff at the Eijkman-Oxford Clinical Research Unit (Decy Subekti, Jeny, Lia Waslia, Damian A. Oyong, and Saraswati Soebianto). Our sincere gratitude to Ayu Nurdiantika for her assistance in the laboratory. Our deep gratitude to Dwi Ari Pujianto and Rintis Noviyanti for their valuable advice during the study and analysis. Our deep gratitude to the Dean of Faculty of Medicine, University of Indonesia, Prof. Dr. Ari Fahrial Syam, PhD, director of IMERI, and Prof. Dr. Badriul Hegar, PhD, for the opportunity to work at the laboratory facility in IMERI.

\section{Author's contribution}

WAH, IM, NFL, IS designed the study. AK was involved in the collection of data, performed the laboratory work, analysed the data and drafted the manuscript. AK, CK, MSD, WAH, FHC, JKB, IM, NFL, IS contributed to the analysis and interpretation of the data. All the authors reviewed and approved the final manuscript. 


\section{Funding}

The work was supported by Bill \& Melinda Gates Foundation through Malaria Transmission Consortium (45114), and the Ministry of Research Technology and Higher Education of Republic of Indonesia (120/SP2H/PTNBH/DRPM/2018).

\section{Availability of data and materials}

The dataset generated by this study is available from the corresponding author upon request.

\section{Ethics approval and consent to participate}

This study has been approved by Ethical committee of Medical Faculty, University of Indonesia no. 37/H2.F1/ETIK/2013. Informed consent was obtained from all study subjects prior to samples taking.

\section{Consent for publication}

Not applicable

\section{Competing interest}

The author(s) declare(s) that they have no competing interests.

\section{Author's details}

${ }^{1} \mathrm{PhD}$ Program in Biomedical Sciences, Medical Faculty, Universitas Indonesia, Jakarta, Indonesia.

${ }^{2}$ Eijkman-Oxford Clinical Research Unit, Jakarta, Indonesia. ${ }^{3}$ Eck Institute for Global Health, University of Notre Dame, Notre Dame, IN, United States. ${ }^{4} \mathrm{PT}$ Epidemiologi Indonesia, Jakarta, Indonesia. ${ }^{5}$ UNICEF, Jakarta, Indonesia. ${ }^{6}$ Center for Tropical Medicine and Global Health, Nuffield Department of Medicine, University of Oxford, United Kingdom. ${ }^{7}$ Infection \& Immunity Division, Walter \& Eliza Hall Institute, Melbourne, Australia. ${ }^{8}$ Department of Parasitology, Medical Faculty, Universitas Indonesia, Jakarta, Indonesia.

\section{References}

1. World Health Organization. Global technical strategy for malaria 2016-2030. World Health Organization; 2015.

2. Hsiang MS, Ntuku H, Roberts KW, Dufour MK, Whittemore B, Tambo M, McCreesh P, Medzihradsky OF, Prach LM, Siloka G, et al. Effectiveness of reactive focal mass drug administration and reactive focal vector control to reduce malaria transmission in the low malaria-endemic setting of Namibia: a cluster-randomised controlled, open-label, two-by-two factorial design trial. Lancet. 2020;395:136173. 
3. Samuels AM, Odero NA, Odongo W, Otieno K, Were V, Shi YP, Sang T, Williamson J, Wiegand R, Hamel $\mathrm{MJ}$, et al: Impact of community-based mass testing and treatment on malaria infection prevalence in a high transmission area of western Kenya: A cluster randomized controlled trial. Clin Infect Dis. 2020.

4. Mulebeke R, Wanzira H, Bukenya F, Eganyu T, Collborn K, Elliot R, Van Geertruyden JP, Echodu D, Yeka A. Implementing population-based mass drug administration for malaria: experience from a high transmission setting in North Eastern Uganda. Malar J. 2019;18:271.

5. Sutanto I, Kosasih A, Elyazar IRF, Simanjuntak DR, Larasati TA, Dahlan MS, Wahid I, Mueller I, Koepfli C, Kusriastuti R, et al. Negligible impact of mass screening and treatment on mesoendemic malaria transmission at West Timor in eastern Indonesia: a cluster-randomized trial. Clin Infect Dis. 2018;67:1364-72.

6. Meibalan E, Marti M. Biology of malaria transmission. Cold Spring Harb Perspect Med. 2017; 7.

7. Nguitragool W, Mueller I, Kumpitak C, Saeseu T, Bantuchai S, Yorsaeng R, Yimsamran S, Maneeboonyang W, Sa-Angchai P, Chaimungkun W, et al. Very high carriage of gametocytes in asymptomatic low-density Plasmodium falciparum and $P$. vivax infections in western Thailand. Parasit Vectors. 2017;10:512.

8. Tadesse FG, van den Hoogen L, Lanke K, Schildkraut J, Tetteh K, Aseffa A, Mamo H, Sauerwein R, Felger I, Drakeley $\mathrm{C}$, et al. The shape of the iceberg: quantification of submicroscopic Plasmodium falciparum and Plasmodium vivax parasitaemia and gametocytaemia in five low endemic settings in Ethiopia. Malar J. 2017;16:99.

9. Coalson JE, Walldorf JA, Cohee LM, Ismail MD, Mathanga D, Cordy RJ, Marti M, Taylor TE, Seydel KB, Laufer MK, Wilson ML. High prevalence of Plasmodium falciparum gametocyte infections in schoolage children using molecular detection: patterns and predictors of risk from a cross-sectional study in southern Malawi. Malar J. 2016; 15:527.

10. Koepfli C, Robinson LJ, Rarau P, Salib M, Sambale N, Wampfler R, Betuela I, Nuitragool W, Barry AE, Siba $P$, et al. Blood-stage parasitaemia and age determine Plasmodium falciparum and $P$. vivax gametocytaemia in Papua New Guinea. PLoS One. 2015;10:e0126747.

11. Omondi P, Burugu M, Matoke-Muhia D, Too E, Nambati EA, Chege W, Musyoka KB, Thiongo K, Otinga $M$, Muregi F, Kimani F. Gametocyte clearance in children, from western Kenya, with uncomplicated Plasmodium falciparum malaria after artemether-lumefantrine or dihydroartemisinin-piperaquine treatment. Malar J. 2019;18:398.

12. Bousema JT, Schneider P, Gouagna LC, Drakeley CJ, Tostmann A, Houben R, Githure JI, Ord R, Sutherland CJ, Omar SA, Sauerwein RW. Moderate effect of artemisinin-based combination therapy on transmission of Plasmodium falciparum. J Infect Dis. 2006;193:1151-9.

13. Sutanto I, Suprijanto S, Kosasih A, Dahlan MS, Syafruddin D, Kusriastuti R, Hawley WA, Lobo NF, Ter Kuile FO. The effect of primaquine on gametocyte development and clearance in the treatment of uncomplicated falciparum malaria with dihydroartemisinin-piperaquine in South sumatra, Western indonesia: an open-label, randomized, controlled trial. Clin Infect Dis. 2013;56:685-93. 
14. Karl S, Laman M, Moore BR, Benjamin JM, Salib M, Lorry L, Maripal S, Siba P, Robinson LJ, Mueller I, Davis TM. Risk factors for Plasmodium falciparum and Plasmodium vivax gametocyte carriage in Papua New Guinean children with uncomplicated malaria. Acta Trop. 2016;160:1-8.

15. Slater HC, Ross A, Felger I, Hofmann NE, Robinson L, Cook J, Goncalves BP, Bjorkman A, Ouedraogo $\mathrm{AL}$, Morris $\mathrm{U}$, et al. The temporal dynamics and infectiousness of subpatent Plasmodium falciparum infections in relation to parasite density. Nat Commun. 2019;10:1433.

16. Waltmann A, Darcy AW, Harris I, Koepfli C, Lodo J, Vahi V, Piziki D, Shanks GD, Barry AE, Whittaker M, et al. High rates of asymptomatic, sub-microscopic Plasmodium vivax infection and disappearing Plasmodium falciparum malaria in an area of low transmission in Solomon Islands. PLoS Negl Trop Dis. 2015;9:e0003758.

17. Hofmann NE, Gruenberg M, Nate E, Ura A, Rodriguez-Rodriguez D, Salib M, Mueller I, Smith TA, Laman M, Robinson LJ, Felger I. Assessment of ultra-sensitive malaria diagnosis versus standard molecular diagnostics for malaria elimination: an in-depth molecular community cross-sectional study. Lancet Infect Dis. 2018;18:1108-16.

18. Nilsson SK, Childs LM, Buckee $C$, Marti M. Targeting human transmission biology for malaria elimination. PLoS Pathog. 2015;11:e1004871.

19. Rovira-Vallbona E, Contreras-Mancilla JJ, Ramirez R, Guzmán-Guzmán M, Carrasco-Escobar G, Llanos-Cuentas A, Vinetz JM, Gamboa D, Rosanas-Urgell A. Predominance of asymptomatic and sub-microscopic infections characterizes the Plasmodium gametocyte reservoir in the Peruvian Amazon. PLoS Negl Trop Dis. 2017;11:e0005674.

20. Lin JT, Ubalee R, Lon C, Balasubramanian S, Kuntawunginn W, Rahman R, Saingam P, Heng TK, Vy D, San S, et al. Microscopic Plasmodium falciparum gametocytemia and infectivity to mosquitoes in Cambodia. J Infect Dis. 2016;213:1491-4.

21. Martins-Campos KM, Kuehn A, Almeida A, Duarte APM, Sampaio VS, Rodriguez ÍC, da Silva SGM, Ríos-Velásquez CM, Lima JBP, Pimenta PFP, et al. Infection of Anopheles aquasalis from symptomatic and asymptomatic Plasmodium vivax infections in Manaus, western Brazilian Amazon. Parasit Vectors. 2018;11:288.

22. Lindblade KA, Steinhardt L, Samuels A, Kachur SP, Slutsker L. The silent threat: asymptomatic parasitemia and malaria transmission. Expert Rev Anti Infect Ther. 2013;11:623-39.

23. Ouédraogo AL, Bousema T, Schneider P, de Vlas SJ, llboudo-Sanogo E, Cuzin-Ouattara N, Nébié I, Roeffen W, Verhave JP, Luty AJ, Sauerwein R. Substantial contribution of submicroscopical Plasmodium falciparum gametocyte carriage to the infectious reservoir in an area of seasonal transmission. PLoS One. 2009;4:e8410.

24. Bousema T, Okell L, Felger I, Drakeley C. Asymptomatic malaria infections: detectability, transmissibility and public health relevance. Nat Rev Microbiol. 2014;12:833-40.

25. Purba IE, Hadi UK, Hakim L. Analisis Pengendalian Malaria Di Provinsi Nusa Tenggara Timur Dan Rencana Strategis Untuk Mencapai Eliminasi Malaria.2017. 
26. Rosanas-Urgell A, Mueller D, Betuela I, Barnadas C, Iga J, Zimmerman PA, del Portillo HA, Siba P, Mueller I, Felger I. Comparison of diagnostic methods for the detection and quantification of the four sympatric Plasmodium species in field samples from Papua New Guinea. Malar J. 2010; 9:361.

27. Wampfler R, Mwingira F, Javati S, Robinson L, Betuela I, Siba P, Beck HP, Mueller I, Felger I. Strategies for detection of Plasmodium species gametocytes. PLoS One. 2013; 8:e76316.

28. Mangold KA, Manson RU, Koay ES, Stephens L, Regner M, Thomson RB Jr, Peterson LR, Kaul KL. Real-time PCR for detection and identification of Plasmodium spp. J Clin Microbiol. 2005;43:243540.

29. Tadesse FG, Slater HC, Chali W, Teelen K, Lanke K, Belachew M, Menberu T, Shumie G, Shitaye G, Okell LC, et al. The Relative Contribution of Symptomatic and Asymptomatic Plasmodium vivax and Plasmodium falciparum Infections to the Infectious Reservoir in a Low-Endemic Setting in Ethiopia. Clin Infect Dis. 2018;66:1883-91.

30. Koepfli C, Schoepflin S, Bretscher M, Lin E, Kiniboro B, Zimmerman PA, Siba P, Smith TA, Mueller I, Felger I. How much remains undetected? Probability of molecular detection of human Plasmodia in the field. PLoS One. 2011;6:e19010.

31. Nixon CP. Plasmodium falciparum gametocyte transit through the cutaneous microvasculature: A new target for malaria transmission blocking vaccines? Hum Vaccin Immunother. 2016;12:3189-95.

32. Schneider P, Bousema JT, Gouagna LC, Otieno S, van de Vegte-Bolmer M, Omar SA, Sauerwein RW. Submicroscopic Plasmodium falciparum gametocyte densities frequently result in mosquito infection. Am J Trop Med Hyg. 2007;76:470-4.

33. Robinson LJ, Wampfler R, Betuela I, Karl S, White MT, Li Wai Suen CS, Hofmann NE, Kinboro B, Waltmann A, Brewster J, et al: Strategies for understanding and reducing the Plasmodium vivax and Plasmodium ovale hypnozoite reservoir in Papua New Guinean children: a randomised placebocontrolled trial and mathematical model. PLoS Med. 2015; 12:e1001891.

34. Eisele TP, Bennett A, Silumbe K, Finn TP, Porter TR, Chalwe V, Hamainza B, Moonga H, Kooma E, Chizema Kawesha E, et al: Impact of Four Rounds of Mass Drug Administration with Dihydroartemisinin-Piperaquine Implemented in Southern Province, Zambia. Am J Trop Med Hyg. 2020.

\section{Figures}




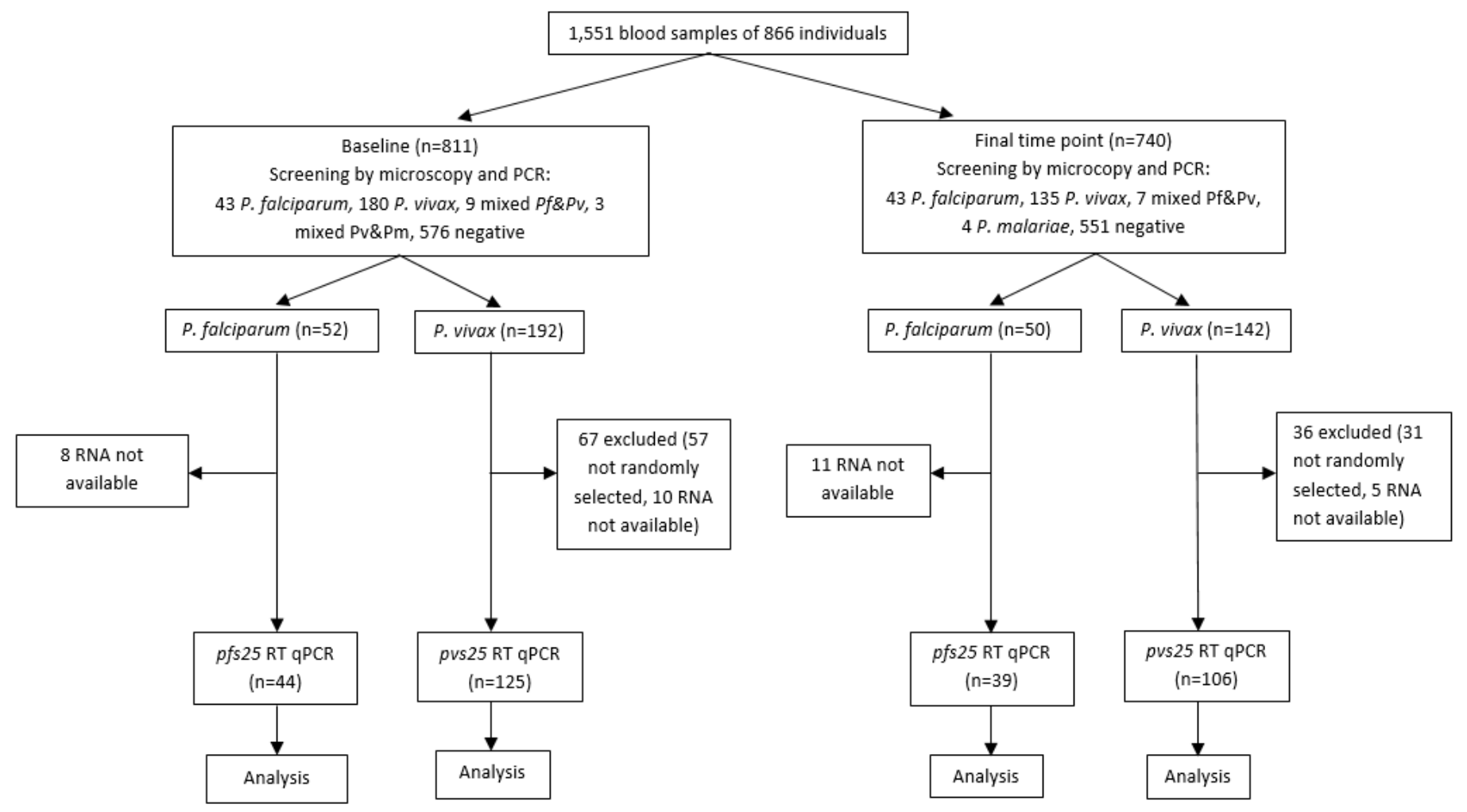

Figure 1

Study framework

A P. falciparum

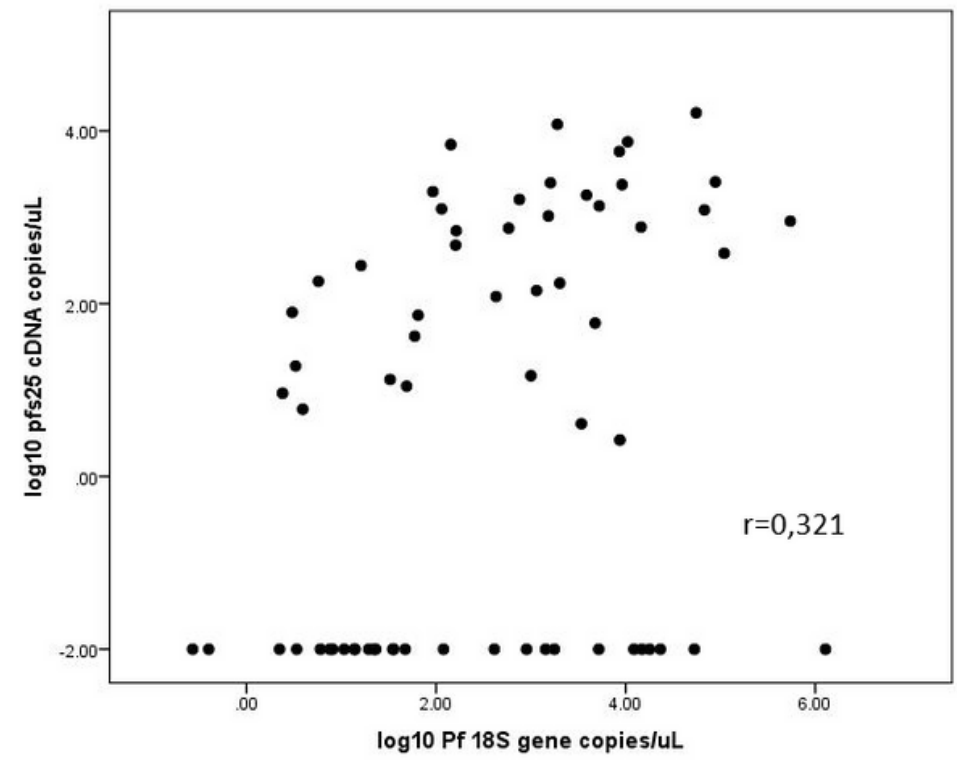

B P. vivax

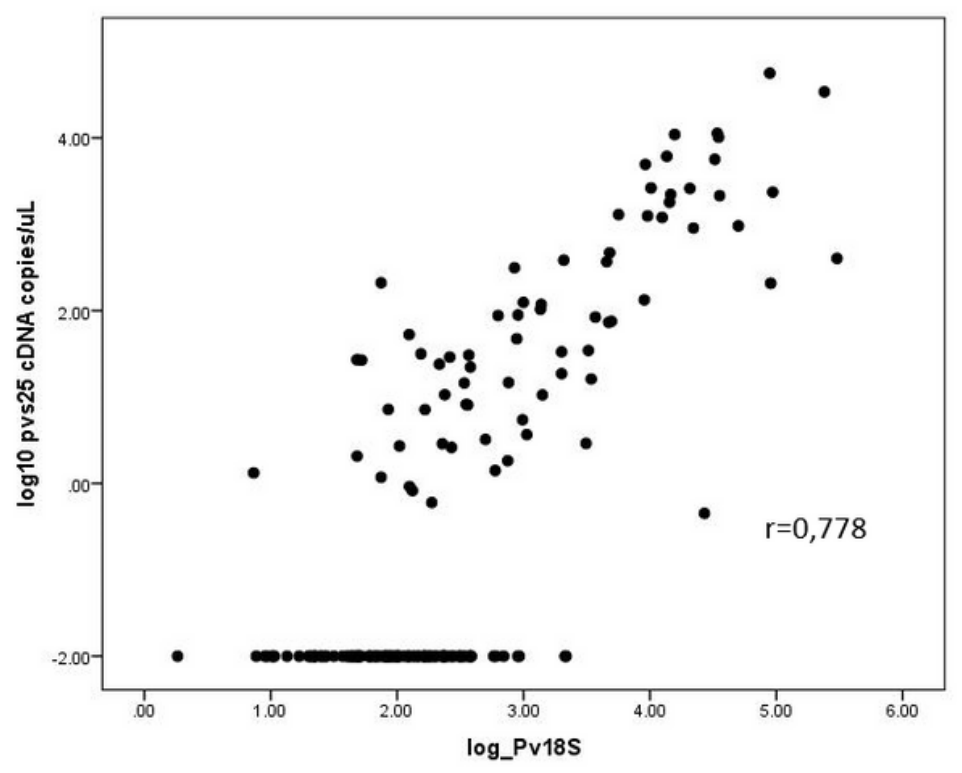

Figure 2

A positive correlation was demonstrated between $18 \mathrm{~S}$ gene copy numbers $/ \mu \mathrm{L}$ and gametocyte transcript numbers/ $\mu \mathrm{L}$ for (A) P. falciparum (pfs25) as well as for (B) P. vivax/pvs25. Linear regression analyses 
both demonstrated a significance correlation $(p<0.001)$.

A

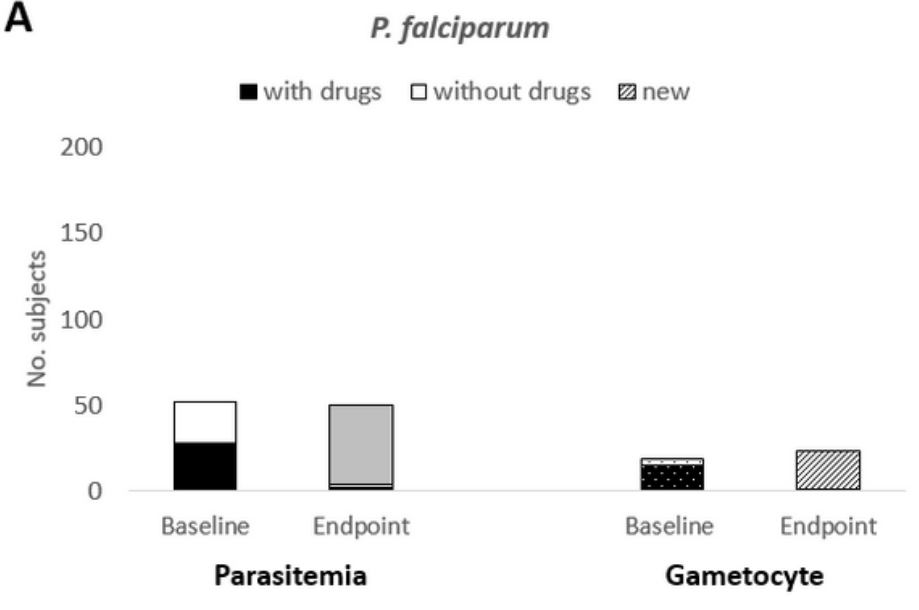

B

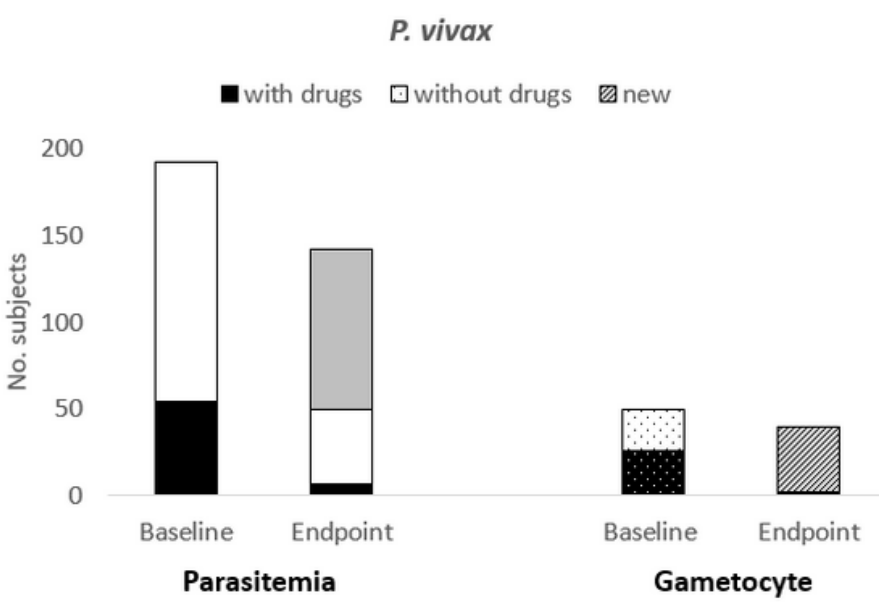

\section{Figure 3}

A. Number of P. falciparum-positive individuals and gametocyte carriers at baseline and endpoint. At baseline, 54\% (28/52) parasitemic subjects were given drugs ( ), and 46\% (24/52) were without drugs ( ). At the endpoint, only two of each subject with and without drugs remained positive. However, 46 new infected subjects ( ) appeared at the endpoint. Furthermore, in gametocyte carriers, similar pattern was observed. Seventy-nine percent (15/19) carriers were given drugs ( ), and 21\% (4/19) were without drugs ( ). At the endpoint, nearly all gametocyte carriers were new subjects $(96 \%=22 / 23$, grey bar $=)$, and only one subject without drugs was diagnosed as positive. B. Number of P. vivax-positive subjects and gametocyte carriers at baseline and endpoint. At baseline, 28\% (54/192) parasitemic subjects were given drugs ( ), and $72 \%$ (138/192) were not given drugs ( ). At the endpoint, six of those with drugs and 43 of those without drugs were found positive. In addition, 93 new infected subjects () appeared. A similar pattern was also observed in gametocyte carriers. Fifty-three percent (26/49) carriers were given drugs ( ), and $47 \%(23 / 49)$ were not given drugs ( ). At the endpoint, majority $(95 \%=37 / 39)$ of gametocyte carriers were new (), while only two (one with drugs and one without drugs) remained as carriers.

\section{Supplementary Files}

This is a list of supplementary files associated with this preprint. Click to download.

- Additionalfile1.docx

- Additionalfile2.docx

- Additionalfile3.docx 